\title{
Case study of transfusion related acute lung injury in intensive care unit
}

\author{
Vasiliki Margari ${ }^{* 1}$, Panagiota Bompou-Magoula² \\ ${ }^{1}$ MITERA Hospital, General Clinic, Athens, Greece \\ ${ }^{2}$ Technological Educational Institute of Athens, Athens, Greece
}

Received: March 2, 2015

DOI: $10.5430 /$ jnep.v5n8p60
Accepted: May 4, 2015

URL: http://dx.doi.org/10.5430/jnep.v5n8p60

\begin{abstract}
Transfusion is a common method of treatment of haemorrhagic events of patients treated in the Intensive Care Unit (ICU). Nonetheless, it involves various dangers, in many cases fatal, such as transfusion related acute lung injury (TRALI). This article refers to the case encountered during our traineeship in the ICU. It is about a 47-year-old man, who was transported to us from another tertiary acute care facility intubated due to diabetic coma. After 39 days of treatment in the ICU, the acute diabetes mellitus, the hemodynamic instability and the electrolyte disorders were regulated. However, he started to have diffuse haemorrhagic events due to intestinal necrosis and required transfusion of blood factors. After the transfusion of Platelets (PLT) he developed Acute Respiratory Distress Syndrome (ARDS), which evolved to TRALI and finally the death of the patient occurred.
\end{abstract}

Key Words: Transfusion related acute lung injury, Blood transfusion reaction, Lung Injury, Intensive Care Unit

\section{INTRODUCTION}

It is an unquestionable fact that nowadays science is constantly evolving. TRALI even today remains a fatal syndrome, which is often confused with ARDS. It is a rare complication following transfusion of blood and blood products and in particular whole blood, Packed Red Blood Cells (PRBC), Platelets (PLT) and Fresh Frozen Plasma (FFP). ${ }^{[1,2]}$ It is a non-cardiogenic pulmonary oedema that often occurs within the first six hours following blood components transfusion. Its frequency, according to international literature, is estimated to occur in 1:5000 transfusions with fatality 5\%$10 \%$ of the total number of transfusions. ${ }^{[2-6]}$ The etiology of the syndrome remains not fully understood; due to that health professionals should report the events ending to TRALI, as well as their way of treatment in order to acquire some type of "experience". In the future, this will improve the possible approaches in order to save the patient's life.

\section{CASE REPORT}

A 47-year-old man was transported to us from a tertiary acute care facility. Prior to this event the patient did not have any severe health problems. The only pathosis were arterial hypertension and hypertriglyceridaemia, which were regulated by prescribed medication. One week before hospitalisation he developed clinical symptoms of polyuria, polydipsia and difficulty in speech. Upon arrival at the first hospital he was intubated due to diabetic coma: blood glucose was 1300 $\mathrm{mg} / \mathrm{dl}$, glycated haemoglobin was $15.5 \%$, serum creatitine $5.0 \mathrm{mg} / \mathrm{dl}$ and his blood pressure was 77/27 mmHg. He developed metabolic acidosis with $\mathrm{pH}=7.15$ and hemodynamic instability under vasopressor agents.

The first problem encountered by the patient were the dia-

*Correspondence: Vasiliki Margari; Email: vickymargari@gmail.com; Address: 18th Alkiviadou str. Agioi Anargiroi, 13561, Athens, Greece. 
betic coma caused by diabetic ketoacidosis, electrolyte disorders and neutropaenia. Table 1 figures the objective examination on admission to hospital and Table 2 shows the first assessment per system.

The patient during the first days of hospitalisation presented polysystemic symptoms, such as oedematous-cyanotic limbs, fever between $38.0^{\circ} \mathrm{C}-39.5^{\circ} \mathrm{C}$, gastroparesis (placement of Levin) and numerous auricular extrasystoles despite the continuous drip of amiodarone. There began to appear points of bedsore with redness at the right and left legs on the sixth day of hospitalisation. On the contrary, he was hemodynamic stable, his oxygenation improved, as well as his lactic acidosis and his diuresis.

On the seventh day the sedation was interrupted, an Electroencephalograph was done which displayed a serious cerebral disfunction, there was no communication or reaction to pain stimuli during clinical examination and at the laboratory respiratory alkalosis was found. During this period gastroparesis was rehabilitated and intestinal feeding began.

Table 1. Objective examination of the patient on his admission to hospital

\begin{tabular}{|ll|}
\hline Objective examination \\
- & Cold limbs (hypotension-tachycardia) \\
- & Miosis (sedation) \\
- & HR thorax: infiltrates in both sides \\
- & Abdomen: soft/rare intestinal sounds \\
- & Oliguria to anuria \\
\hline
\end{tabular}

Table 2. First assessment of the patient on his admission per system

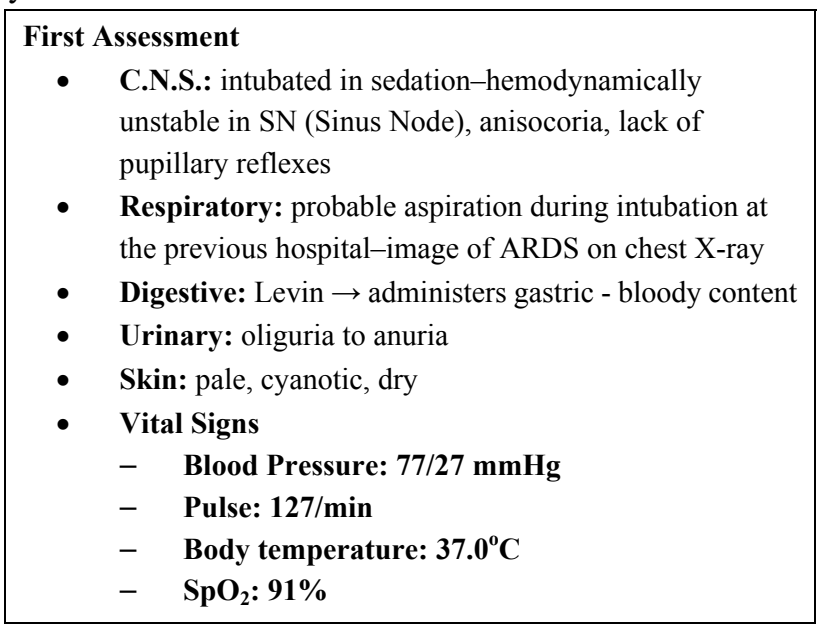

During the first 48 hours after sedation was discontinued, the patient did not show any neurologic improvement during clinical examination, which called for brain MRI that de- tected diffuse anoxaemic damage. The results of laboratory tests showed decreased white blood cells $\left(1500 \times 10^{6} / \mu \mathrm{l}\right)$.

Due to persistent fever, a tracheotomy was made with the creation of temporary tracheostomy and change of central venous catheter. Moreover, a gas tube was placed due to severe diarrhoeic evacuation. However, neurologic improvement was noticed (automatic cough, slight finger movement of the upper limbs to pain stimuli, isocoria, eye movement upon command, expression on pain). The communication with the patient was gradually re-established and he was able to "contact" people surrounding him, even watch television.

During the following ten days of his hospitalisation, his fever became higher $\left(38.5^{\circ} \mathrm{C}-39.3^{\circ} \mathrm{C}\right)$, without corresponding to cold compresses and paracetamol administration. Due to many hypotensive episodes a blood work of FT4 (4.8), FT3 (0.9), FSH (<0.3), LH $(<0.4)$ and TSH $(<0.186)$ was ordered that suggested Pituitary deficiency. Additionally, due to low FHS and LH a brain MRI took place that confirmed the firsth hypothesis. Many purulent and bloody secretions appeared in the lower respiratory system during suction. Additionally, he was transfused for two consecutive days $\left(13^{\text {nd }}-14^{\text {th }}\right)$ with 1 Unit of Packed Red Blood Cells (PRBC) each day, due to low haemoglobin. On the $14^{\text {th }}$ day the patient was gradually released from the mechanical respiratory support (placement of T-tube) with satisfactory level of arterial blood gases.

The persistent high fever led to research of the underlying cause with the following actions:

(1) Change of central venous catheter and culture of its tip

(2) Interruption of Pentaglobin (immunoreaction)

(3) Thorax - Abdomen CT

(4) Gastroscopy and Proctoscopy

The Gastroscopy revealed several oesophageal ulcerative lesions, which were attributed to the presence of nasogastric feeding line (Levin). These actions did not reveal the etiology of persistent fever.

Transfusions of PRBC continued at regular intervals until the day he died due to seriously low haemoglobin $(\mathrm{Hb}=5.8 \mathrm{~g} / \mathrm{dl})$. The cardiac rhythm alternated between atrial fibrillation and sinusal rhythm with extrasystoles.

For further and more detailed examination of the lower gastrointestinal (bloody stools), the $16^{\text {th }}$ day of hospitalization anosigmoidoscopy - colonoscopy were done, which showed ischemic rectosigmoiditis.

On the $22^{\text {nd }}$ day incidence of hypoxaemia, numerous haemorrhagic diarrhoeic evacuations (placement of flexi-seal) were noticed due to increased prothrombin time (18.1 sec), INR (1.75) and APTT (46.2 sec), as well as extensive oedema. 
The following day, a thorax-upper and lower abdomen CT was done to the patient, which showed an image of air leakage. The same day, during palpation, acute surgical abdomen was noticed and the patient was delivered to the operating room for exploratory laparotomy. Necrotic surfaces on the large intestine were detected, which were removed and a colostomy was formed.

The first day after the surgery the patient did not produce sufficient quantity of urine, he developed serious hypokalaemia and was placed under continuous extrarenal clearance. The $32^{\text {nd }}$ day of hospitalization because of bowel perforation and peritonitis a second surgery took place (colon laparotomy). In that surgery local petechial lesions of the small bowel serosa were observed. Nonetheless, on the $37^{\text {th }}$ day the patient underwent a third surgery, this time an exploratory laparotomy due to ischemic lesions of the colon. A total colectomy and ileostomy was performed.

On the $35^{\text {th }}$ day of hospitalization the patient other than intestine bleeding showed intensive posterior epistaxis from the left nasal fossa and blood flow in the throat, therefore nasal tamponade was placed.

Table 3. Vital signs and Arterial Blood Gases (ABG) of the last 24 hours

\begin{tabular}{llllll}
\hline Hours & $\begin{array}{l}\text { Blood } \\
\text { Pressure } \\
(\mathbf{m m H g})\end{array}$ & $\begin{array}{l}\text { Tempe- } \\
\text { rature } \\
\left(\mathbf{(}^{\mathbf{0}} \mathbf{C}\right)\end{array}$ & $\begin{array}{l}\text { Heart } \\
\text { Rate } \\
(/ \mathbf{m i n})\end{array}$ & $\begin{array}{l}\mathrm{SaO}_{2} \\
(\%)\end{array}$ & $\begin{array}{l}\mathbf{P a O}_{2} \\
(\%)\end{array}$ \\
\hline 07:00 & $140 / 68$ & 36.7 & 85 & 83.7 & 52.3 \\
10:00 & $146 / 70$ & 36.8 & 89 & 89.0 & 58.9 \\
13:00 & $138 / 62$ & 36.7 & 83 & 83.9 & 130 \\
15:00 & $140 / 65$ & 37.9 & 85 & 85.3 & 50.1 \\
16:00 & $141 / 65$ & 38.0 & 86 & 82.5 & 49.2 \\
18:00 & $142 / 68$ & 37.6 & 87 & 76.0 & 44.1 \\
21:00 & $140 / 63$ & 36.8 & 85 & 75.1 & 51.5 \\
23:00 & $95 / 41$ & 36.8 & 87 & - & - \\
01:00 & $85 / 35$ & 37.0 & 82 & 70.9 & 120 \\
02:00 & $64 / 30$ & 36.7 & 38 & 67.5 & 46.1 \\
03:00 & $51 / 12$ & 36.6 & 30 & 47.9 & 36.1 \\
04:00 & $155 / 33$ & 37.0 & 99 & 65.1 & 45.9 \\
05:00 & $100 / 42$ & 37.3 & 55 & - & - \\
\hline
\end{tabular}

During the last week, because multisystemic intensive bleeding continued, transfusions with PRBC, FFP and PLT were done. At the 38th day of hospitalization at 19:00 the patient was transfused with 2 PLT. Four hours after the transfusion, as shown in Table 3, the patient showed severe hypotension and hypoxia. Symptoms during the next three hours intensified, despite fully supported mechanical ventilation and inotropic support. At 02:00 the patient had severe bradycar- dia with hemodynamic instability and he was administered $2 \mathrm{mg}$ of atropine and $1 \mathrm{mg}$ of adrenaline. At 03:00 he showed cardiac asystole and chest compressions along with high inotropic support started, without response. After two hours of ongoing effort the patient died.

\section{Discussion}

In 1818 James Blundell performed the first blood transfusion. It has been a long time since then and procedures have become safer for patients, thus reducing the danger of transmission of diseases and complications. ${ }^{[2]}$

Only in 2004 TRALI was officially recognised during a conference held at Toronto by the National Institute of Health as a severe complication of blood transfusion and was clinically separated from Acute Lung Injury (ALI) which until then was not connected to it. The clinical features of TRALI are dyspnea, hypoxaemia and infiltrations of lungs in both sides that appear on chest X-ray. ${ }^{[7-11]}$ There are no reports for a differential frequency of appearance of TRALI according to gender or the age of the patient. ${ }^{[2]}$

Pathophysiology of TRALI is ambiguous and has not been fully understood. However, its etiology is based on the wellknown "two-hit" hypothesis which includes the clinical condition (pre-existing pathology - first hit) of the patient and the transfusion of blood products, especially plasma (second hit). ${ }^{[2,11-14]}$

The vast majority of cases mention that the pre-existence of HLA class I, class II and HNA antibodies in the plasma of the donor, react with the neutrophils of the already very sensitive pulmonary mucosa. In a very smaller percentage of cases, it is reported that the pre-existing heavy pathology of the patient could result in a systemic inflammation of lungs which leads to the accumulation of neutrophils in their microvasculature. These neutrophils are highly possible to react to lipids or other mediators (CD40L) accumulated in the blood cell components during its storage and contribute to the endothelial damage of the patients in severe condition, thus causing vascular leakage and pulmonary oedema. A different hypothesis claims that mtDNA (mithchondrial DNA) DAMPs (Damage-Associated Molecular Pattern molecules) appear in PRBC, FFP and PLT, possibly contributing to the creation of TRALI. However, further research is required for the proof of this hypothesis. ${ }^{[2,12,13,15]}$

In many cases TRALI is confused with other diseases. Therefore, possible causes of acute pulmonary oedema should be excluded, which may be acute haemolytic reaction, pneumonia and cardiogenic pulmonary oedema. ${ }^{[5]}$ Following the exclusion of the above, the most basic and most differential diagnosis from TRALI is TACO (Transfusion-Associated 
Circulatory Overload), which is characterised by circulatory overload. Despite the fact that there are not specific examinations for TRALI diagnosis, the following clinical examinations may confirm the suspicion of its presence:

- Echocardiogram

- White blood cell count (WBC)

- Brain natriuretic peptide (BNP)

- Pulmonary oedema fluid protein analysis ${ }^{[11]}$

Supportive care is the only treatment for patients suffering from TRALI, which is confirmed both by a wide literature and clinically. ${ }^{[5]}$ Use of diuretics are indicated when the patient suffering from TRALI presents circulatory overload in order to improve their condition, but they should be avoided in other cases. ${ }^{[6,16]}$ In the above described case there were oedemas and positive fluid balance, so the use of diuretics preceded the appearance of TRALI and continued until the end.

As there is not specialised treatment of TRALI, the health professionals should focus on prevention measures. According to scientific research, prevention is based on three main measures. The first one focuses on the strict selection of donor. In 2003 the English National Blood Service applied the exclusion of women from FFP donation and within 6 years significant reduction of TRALI patients was noticed. ${ }^{[2,17-20]}$ The same measure is applied in Greece despite the lack of registered percentages. The second measure concerns the strict methods of storage of blood and its products, especially FFP. The third and last measure refers to the avoidance of unnecessary transfusions. ${ }^{[13,18,21,22]}$

The case presented in this article fully confirms the theory of the "two-hit" model. In particular, the impaired state of the patient combined with the last PLT transfusion resulted in TRALI. The vital signs and ABG of the patient as developed within the first six hours following the transfusion confirm this syndrome based on literature. The diagnosis of the syndrome could be challenged, because of the constant transfusions during hospitalization. Nevertheless, this case follows the course of development of TRALI, with intense and sudden drop in blood pressure, hypoxia-despite mechanical ventilation-and fever that was treated with antipyretic drugs.

\section{Conclusion}

TRALI is considered one of the most basic reasons of death in the ICU due to onset of non-cardiogenic pulmonary oedema, a fact that is also claimed by numerous articles, as well as by this case. The analysis and study of the case led to the conclusion that both physicians and nurses, who are responsible for the treatment of seriously ill patients should be able to recognise and proceed to differential diagnosis of TRALI correctly and on time.

In conclusion, it should be emphasized that in every blood and blood products transfusion (PRBC, FFP, PLT), regardless of the number of transfusions, health professionals should be vigilant for the possible development of TRALI.

\section{ACKNOWLEDGeMENTS}

Upon completion of this article we would like to thank Ms. Prasini Ioanna, Head of Clinical Training for her encouragement and her precious help, as well as, Dr. Kaskantamis Andreas, Physician Anaesthesiologist - Intensivist for the information and clarifications regarding this case. Finally, we would like to thank Mr. Papageorgiou Dimitris, Professor of Applications at TEI of Athens for his advice and support.

\section{CONFLICTS OF INTEREST Disclosure}

The authors declare that there is no conflict of interest statement.

\section{REFERENCES}

[1] Aravinthan A, Sen S, Markus N. Transfusion-related acute lung injury: A rare and life-threatening complication of a common procedure. Clin Med. 2009; 9: 87-89. http://dx.doi.org/10.7861 /clinmedicine.9-1-87

[2] Jaworski K, Maslanka K, Kosior DA. Transfusion-related acute lung injury: A dangerous and underdiagnosed noncardiogenic pulmonary oedema. Cardiology Journal. 2013; 20(4): 337-344. PMid:23913451 http://dx.doi.org/10.5603/CJ.2013.0091

[3] Bux J. Transfusion-related acute lung injury (TRALI): a serious adverse event of blood transfusion. Vox Sang. 2005; 89(1): 110. PMid:15938734 http://dx.doi.org/10.1111/j.1423-041 $0.2005 .00648 \cdot x$

Published by Sciedu Press
[4] Muller JY. Le TRALI du diagnostic à la prevention. Transfusion and Apheresis Science. 2005; 12: 95-102.

[5] Vlaar APJ, Juffermans NP. Transfusion-related acute lung injury: a clinical review. Lancet. 2013; 382: 984-94. http://dx.doi.org /10.1016/S0140-6736(12) 62197-7

[6] Torbati SS, Schlesinger S, Niku D. Acute respiratory failure during routin blood transfusion: A case report and review of the literature. Clinical Communication: Adults. 2013; 46(3): 341-344.

[7] Swanson K, Dwyre DM, Krochmal J, et al. Transfusion-Related Acute Lung Injury (TRALI): Current Clinical and Pathophysiologic Considerations. Lang. 2006; 184: 177-185. http://dx.doi.org /10.1007/s00408-005-2578-8

[8] Bernasinski M, Mertes PM, Carlier M, et al. Les complications respi- 
ratoires de la transfusion. Transfusion Clinique et Biologique. 2014; 21: 60-65. PMid:24814817 http://dx.doi.org/10.1016/j.t racli.2014.03.002

[9] Ritu K, Sanjay B, Jalees F, et al. Acute lung injury after platelet transfusion in a patient with dengue fever. Asian Journal of Transfusion Science. 2014; 8(2): 131-134. PMid:25161356 http://dx.doi.o rg/10.4103/0973-6247.137455

[10] Schweisfurth H, Sopivnik I, Moog R. Transfusion-related acute lung injury (TRALI). Pneumologie. 2014; 68(09): 599-603. PMid:25046684 http://dx.doi.org/10.1055/s-0034-13773 33

[11] Sayah DM, Looney MR, Toy P. Transfusion Reactions: Newer Concepts on the Pathophysiology, Incidence, Treatment and Prevention of Transfusion Related Acute Lung Injury (TRALI). Crit Care Clin. 2012; 28(3): 363-372. PMid:22713611 http://dx.doi.org/10 1016/j.ccc. 2012.04.001

[12] Land WG. Transfusion-related acute lung injury: The work of DAMPs. Transfusion Medicine and Hemotherapy. 2013; 40(1): 3-13. PMid:23637644 http://dx.doi.org/10.1159/000345688

[13] Torres MD, Torres A, Cuellar F, et al. Evolutionary computation in the identification of risk factors. Case ofTRALI. Expert Systems with Applications. 2013; 41: 831-840. http://dx.doi.org/10.1016 /j.eswa.2013.08.013

[14] Alam A, Huang M, Yi QL, et al. Perioperative transfusion-related acute lung injury: The Canadian Blood Services experience. Transfusion and Apheresis Science. 2014; 50: 392-398. PMid:24797240 http://dx.doi.org/10.1016/j.transci.2014.04.008

[15] Lee YL, King MB, Gonzalez RP, et al. Blood Transfusion Products Contain Mitochondrial Dna Damps: A Potential Effector of
Transfusion Related Acute Lung Injury. Journal of Surgical Research. 2014.

[16] Schmidt AE, Adamski J. Education Committee of the Academy of Clinical Laboratory Physicians and Scientists. Pathology consultation on transfusion-related acute lung injury (TRALI). Am J Clin Pathol. 2012; 138(4): 498-503. PMid:23010703 http://dx.doi .org/10. 1309/AJCPFF6JKXM7BYOI

[17] Benson AB, Austin GL, Berg M, et al. Transfusion-related acute lung injury in ICU patients admitted with gastrointestinal bleeding. Intensive Care Med. 2010; 36(10): 1710-1717. PMid:20658125 http://dx.doi.org/10.1007/s00134-010-1954-x

[18] Velthove KJ, Strengers PFW. Blood, blood components, plasma, and plasma products. Side Effects of Drugs, Annual 35. Edited by J.K. Aronson; 2014.

[19] Liu K, Chen HL, You QS, et al. The relationship between total red blood cells and plasma transfusion and acute lung injury risk after cardiac surgery: A retrospective study. Transfusion and Apheresis Science. 2014; 50: 427-432. PMid:24661845 http://dx.doi.org $/ 10.1016 / j$.transci.2014.03.001

[20] Vlaar APJ. Transfusion-related acute lung injury: Current understanding and preventive strategies. Transfusion Clinique et Biologique. 2012; 19: 117-124. PMid:22682310 http://dx.doi.org/10.10 16/j.tracli.2012.03.001

[21] Soni N. Transfusion related acute lung injury. TRALI. Current Anaesthesia \& Critical Care. 2009; 20: 93-97.

[22] Renaudier P, Rebibo D, Waller C, et al. Complication pulmonaire de la transfusion. Transfusion Clinique et Biologique. 2009; 16: 218232. PMid:19446484 http://dx.doi.org/10.1016/j.tracli. 2009.04 .008 